\title{
Thomas A. Lee Whiting, Davide Domenici, Víctor Manuel Esponda Jimeno y Carlos Uriel del Carpio Penagos (coords.) (2009), Medio ambiente, antropología, historia y poder regional en el occidente de Chiapas y el Istmo de Tehuantepec, Tuxtla Gutiérrez, Chiapas, México: Universidad de Ciencias y Artes de Chiapas.
}

Justus Fenner

S i arqueólogos, antropólogos, etnohistoriadores, historiadores, lingüistas y arquitectos se juntan para discutir un tema que a todos ellos interesa, podemos estar seguros de que los resultados serán más llamativos e ilustradores que cuando los expertos de una sola disciplina se juntan para discutir el mismo tema. Son el trabajo y la discusión multidisciplinarios los que nos permiten reconstruir una época, región o cultura con mayor precisión y con colores más fuertes y limpios.

El libro, coordinado por las personas arriba mencionadas, es precisamente el resultado de un esfuerzo multidisciplinario. No es perfecto - realmente pocos libros lo son- pero da un paso importante al presentar resultados nuevos para estimular la discusión y la futura investigación sobre una de las regiones del estado de Chiapas poco contemplada por un público amplio.

Lo que nos presentan en esta antología es una región y su historia desde tiempos precoloniales hasta el presente. Es la región de la llamada Selva Zoque, zona antes conocida como el Desierto de Tuxtla, o partes de ella, como el departamento Mezcalapa oel departamento El Progreso. Otros subsuman actualmente la zona bajo la toponimia de Las Chimalapas. Es la parte de Chiapas colindante con Oaxaca desde el cerro de La Jineta que incluye los municipios de Jiquipilas, Cintalapa, Ocozocoautla y el extinto Quechula, subiendo hasta la confluencia del río Amacohuite con el río Grijalva, en las cercanías del cerro del Mono Pelado, que es el punto de unión entre Chiapas, Tabasco y Veracruz. Vista así, resulta una región artificialmente creada por el trazo de límites — antes nacionales, hoy internos-, pero los autores dejan claro que lo que se considera la Selva Zoque se expande más allá de los límites estatales hacia áreas correspondientes a Oaxaca, Veracruz y Tabasco, hecho que, como vamos a ver, contribuye a la actual tensa situación social y política.

La lectura de este libro ha sido enormemente enriquecedora para mí, en tanto que me apercibí de qué poca cosa sé sobre esta región occidental del estado en el que he vivido los últimos 25 años, y qué poca energía había gastado en mis investigaciones para conocer más sobre lo que en el pasado ha sido la región zoque y lo que es hoy. Mis ojos de historiador, igual que los de muchos otros, han estado más enfocados en las tres regiones chiapanecas clásicas de investigación en las últimas décadas: Los Altos, la Selva Lacandona y el Soconusco,

Justus Fenner, investigador del PROIMMSE-IIA-UNAM 
con sólo algunos sobrevuelos sobre la zona de los Valles Centrales y la zona Norte. Sin embargo, después de haber leído el libro me di cuenta de que mi desatención casi completa hacia esta zona colindante con Oaxaca no tiene ninguna justificación. No sólo comprendí que hay allí una historia clave que permite identificar esta región como parte integral de la zona mixe-zoque que durante la larga época precolonial había generado tantos impulsos culturales que impactaron en las demás culturas mesoamericanas-, sino que también los autores me hicieron recordar que hay una historia reciente que ubica la región zoque chiapaneca y su complemento oaxaqueño - las Chimalapas - en un contexto doloroso y controvertido del Chiapas actual, y con ello de México y del mundo: la migración, el narcotráfico, la depredación del medioambiente, la miseria en el agro, la pobreza o la inseguridad jurídica, al igual que la incapacidad de las autoridades para resolver conflictos provocados, por ejemplo, por los recovecos jurídicos que utilizan los grupos en el poder para aprovecharse de estos vacíos y apoderarse de los recursos y vidas de la gente, quienes no tienen más opción que seguir viviendo una vida que no les brinda la mejora que han estado buscando por tanto tiempo para sus familias.

El día que empecé a leer el libro (27 de enero de 2011), Chimalapas - la partechiapaneca- nuevamente estuvo en la prensa. Había llegado el secretario de la Reforma Agraria en gira para entregar 56 carpetas básicas que, como dijo, darían "plena certeza jurídica en la tenencia de la tierra" a igual cantidad de núcleos agrarios chiapanecos. Mencionó en este acto a las Chimalapas y encargó la atención especial de sus problemas agrarios al subsecretario responsable del Ordenamiento de la Propiedad Rural. Al leer estas líneas y los dos capítulos de este libro que se refieren específicamente a esta zona compartida entre los dos estados, Chiapas y Oaxaca, fui poco a poco recordando lo que había leído años atrás durante los ochenta y noventa y que había casi olvidado: un virulento conflicto de límites entre Chiapas y Oaxaca; la presencia de los "órganos del orden" para evitar la formación de colonias de oaxaqueños en lo que se consideraba tierra de Chiapas; los enfrentamientos entre colonos procedentes de ambos lados del límite entre estados; los reportes sobre los ominosos camiones que, a pesar del conflicto, a diario salían impunemente de la zona cargados con maderas preciosas y, en este mismo contexto, las denuncias contra altos mandos del gobierno del Gral. Absalón Castellanos, quienes supuestamente estaban involucrados en este negocio ilícito. Más recientemente, ya en tiempos de Zedillo, el llamado Megaproyecto del Istmo motivó la lucha de dos comunidades - Santa María y San Miguel Chimalapa - contra la tala ilegal, contra un narco invisible que utilizaba $-\mathrm{y}$ probablemente utilizapistas clandestinas en las Chimalapas para el transporte de la droga, y contra la presencia del ejército. En respuesta a esta lucha, circularon acusaciones que señalaron a los habitantes de la región y a las ONG que los apoyaron como parte de una guerrilla al estilo zapatista. Muy recientes todavía son las informaciones sobre el dramático desgajamiento del cerro Juan de Grijalva y la construcción de la tristemente célebre primera ciudad rural del mismo nombre, formada por desplazados de - precisamente- esta zona.

Ya desde hace muchos años toda la franja sobre ambos lados del límite estatal ha sido un foco rojo constante, pero sin que se hayan encontrado o hecho esfuerzos serios para disipar la situación conflictiva. Y ahora, al leer este libro, comprendí la triste realidad que poco o nada ha cambiado en estos últimos diez años.

La información arqueológica contenida en los primeros capítulos de este libro nos permite comprender las diferentes formas de asentamientos en la Selva del Ocote durante las épocas clásicas y posclásicas mayas y concebirla como una región de colonización y, en otro momento, como región de refugio estratégico frente a nuevas fuerzas que amenazaban desde afuera. Sorprendente como puede parecer, este matiz de colonización y de refugio se ha conservado hasta tiempos 
actuales. La región sigue siendo una zona de colonización con la presencia de nuevos colonos de diferentes partes de la nación mexicana y de otras partes del mismo estado de Chiapas, principalmente de Los Altos. Y, por su poca comunicación e inaccesibilidad, sigue siendo una zona de refugio donde se cruzan los caminos clandestinos del narcotráfico y de los taladores ilegales de madera, y donde las veredas son utilizadas por centroamericanos en su trayectoria hacia la frontera norte del país.

Colindando con el Istmo de Tehuantepec, la zona en cuestión había sido frontera desde mediados del siglo XVI entre la Audiencia de los Confines de Guatemala — después de la Intendencia de Guatemala- y la Nueva España. Y siguió siendo frontera aún después de la Independencia en 1823-1824, cuando en un estado de indefinición política, y sin corresponder ni a Guatemala ni a México, colindaba con la recién formada provincia mexicana (del Istmo) de Tehuantepec que la joven República había organizado para defender sus intereses estratégicos en este cuello de botella que prometía ser la primera comunicación interoceánica. Al anexarse Chiapas a México en 1824, el sentido peligro para el Istmo desapareció, la provincia de Tehuantepec volvió a desaparecer, y la otrora frontera entre dos Repúblicas se volvió un límite interno.

A pesar de haber sido frontera durante tres siglos, nunca se lograron fijar la línea ni sus mojones con precisión, hecho que iba a causar una serie de conflictos entre Chiapas y los estados vecinos de Oaxaca, Veracruz y Tabasco.

Dos artículos en este libro retoman este conflicto de límites: el primero, "El conflicto agrario en los límites de Chiapas y Oaxaca: su trasfondo político", de Coutiño Farrera, resulta ser, antes que un artículo académico, una polémica política que insiste en que los terrenos en disputa han sido siempre parte del estado de Chiapas, precisamente del municipio de Cintalapa. Pero a pesar de un interesante recorrido histórico, la insistencia del autor no encuentra prueba fehaciente que sustente el supuesto hecho de pertenencia de estas tierras a Chiapas. Él hace caso omiso a su propia observación de que no existen trazos claros que definan la colindancia de ambos estados, lo que convierte su artículo en una defensa nada convincente de los derechos chiapanecos.

El segundo artículo, del Dr. Carlos Uriel del Carpio, chiapaneco por cierto, no comparte la aparente certeza de Coutiño Farrera. "Sostengo", dice el autor:

[...] que la república de indios formada por los zoques chimalapas, vale decir, el área que los zoques dicen haber comprado en 1687, abarcaba un territorio que iba desde Santa María Chimalapa hasta Santa María de la Pita, localidad ubicada cerca de la desembocadura del río la Venta en el bajo Grijalva.

Para él, la existencia de las ruinas del antiguo pueblo llamado Santa María Magdalena de la Pita ubicado en los márgenes del río Negro, podría ser la prueba de que sus tierras habían pertenecido a las comunidades del lado oaxaqueño donde todavía existe su lugar homólogo, Santa María Chimalapa, igual que éste fundado por los dominicos en las márgenes de otro río Negro. Supongo que río Negro es otro nombre para el río que otros llaman del Pueblo Viejo o río Magdalena de las Pitas, como lo registra Lucas Alamán en 1836. Pero frente a las pruebas documentales que otro autor, Víctor Esponda Jimeno, presenta en este libro sobre la pertenencia de este pueblo extinguido a la Audiencia de Guatemala, y con ella a la antigua provincia de Chiapas, la hipótesis de Del Carpio resulta poco probable.

En cierta manera este libro representa las dos posiciones que hoy están en pugna, aunque no hay ningún oaxaqueño que presente su versión. Cuando se trata de aportar datos fidedignos que pueden contribuir a esclarecer la pertenencia histórica de este pueblo, y con ello de la región límite entre ambos estados, ambas posiciones se pierden: una en los terrenos del discurso político sin fundamento histórico, y la segunda en la especulación. 
Aunque la tentación de los autores por tomar partido debe haber sido grande, finalmente deben comprender que no es su función volverse jueces en un pleito político entre dos estados, posicionamiento además peligroso cuando ambos desconocen una serie de detalles. En realidad, el caso es más enredado de lo que los autores sospechan. Veamos.

En 1887, el empresario y especulador alemán Karl (Carlos) Eisenmann obtiene la concesión para deslindar los terrenos baldíos de "la parte Sud Este de los Estados de Oaxaca y Veracruz en sus límites con los de Chiapas y Tabasco en la zona situada al Poniente del Río Grijalva y entre los $4^{\underline{0}}$ y $5^{\underline{0}} 30$ de longitud Este del meridiano de México".

Desconociendo por completo la línea fronteriza entre Oaxaca y Chiapas, los agrimensores o topógrafos de Eisenmann reclaman y deslindan tierras que otra compañía deslindadora, la compañía alemana Luis Hüller \& Cía, reclama como de su competencia por su derecho exclusivo de deslinde en el estado de Chiapas. Durante un año, el consiguiente pleito frente a la Secretaría de Fomento bloquea cualquier deslinde de las tierras, hasta que finalmente Hüller compra a Eisenmann su concesión por 20000 pesos y reinicia los trabajos técnicos topográficos.

Pero ojo... Hüller no tenía necesidad de comprar un derechoque Eisenmann sostenía sobre tierras chiapanecas -ya tenía élla concesión exclusiva - Más bien,él compra la concesión para no ejercerla y así realizar sin intromisión de nadie el deslinde de los baldíos en Chiapas.

¿Pero los topógrafos de Hüller iban a reconocer mejor que sus colegas, que trabajaron para Eisenmann, el trazo preciso del límite? En su informe, el mismo ingeniero en jefe, Ismael Loya, después de aclarar que el deslindado Desierto es parte del departamento de Tuxtla y que colinda con Oaxaca, Veracruz y Tabasco, aclara a Fomento lo siguiente:

Como los límites de estos Estados en esa parte son completamente desconocidos, puesto que nunca se han precisado sobre el terreno, esto da lugar a que no se puede saber la extensión de Chiapas por esa parte así como también si todo el Desierto le pertenece, aunque es probable que a los otros Estados mencionados les pertenezca también en una pequeña parte.

A pesar de esta incertidumbre total, los topógrafos, bajo el mando de Loya, se meten en esta zona de difícil acceso y definen por sí solos el trayecto de la supuesta línea fronteriza entre ambos estados, que a la vez delimita los supuestos baldíos del estado de Chiapas. El expediente técnico en el Juzgado de Distrito demuestra claramente que en ningún momento se cita a posibles colindantes chiapanecos ni oaxaqueños. Es decir, en aquel momento la definición de la línea fronteriza estaba enteramente en manos de una empresa particular extranjera interesada en detectar un máximo de tierras baldías para ella y para el gobierno federal, tal como estipula su concesión.

No hay ninguna información que nos pueda indicar que los topógrafos a cargo del deslinde hayan estado conscientes de que sus trabajos topográficos en ese momento rebasaban el simple deslinde de baldíos, volviendo sus diligencias actos de soberanía de uno de los dos estados, el de Chiapas, y dejando posibles derechos de Oaxaca a la deriva. No había presencia de colindantes ni había en esta zona límites naturales que pudieran servir como claras marcas de un límite entre los dos estados. Entonces valdría preguntarse... ien qué se guiaron para trazar la línea de más de cien kilómetros?

El expediente de la justicia federal nos da unas pistas interesantes: hay cuatro actas levantadas frente a las autoridades locales de la zona en donde se hace constar la acción topográfica realizada o planteada.

La primera en Quechula: de la cruz de la iglesia de Quechula por todo el Grijalva hasta la boca del río Amacohite y prolongándola después por el interior del Desierto hasta el Cerro del Mono Pelado en que termina dicha mensura, para enlazarla después con la línea que debía de partir del cerro de La Jineta. 
La segunda en Ocozocoautla, donde hacen constar haber realizado... "Las operaciones de deslinde de que se trata en todo el trayecto de Quechula a Cintalapa y siguiendo los caminos nacionales de esos pueblos a este."

En fecha posterior, el juez de Cintalapa confirma que Loya "...partiendo de un punto llamado "Cerro de la Gineta”, dio principio de la última menzura que le faltaba, continuándola por el interior del Desierto hasta un punto llamado Cerro del Mono Pelado en que deberá terminar dicha menzura."

Y la autoridad de la montería de la Venta de la familia Maldonado se prestó a confirmar que "dichas operaciones [terminaron] en el Cerro llamado Mono Pelado."

Las actas simplemente confirman que el grupo de topógrafos midió alguna parte del Desierto, pero nadie sabía con certeza dónde. Tal vez en esta medición de baldíos, aceptada posteriormente por la Secretaría de Fomento como válida, encontramos uno de los puntos clave para entender el conflicto de hoy.

Pero independientemente de lo anterior, el informe referido nos confronta con otros interesantes aspectos: cuando nos habla de la población de la región considerada baldía nos dice que sólo existen algunas ruinas antiguas de un pueblo colonial al borde del río Pueblo Viejo y grutas en las que encontraron "trastos, como ollas, cazuelas, etcétera, que por lo toscamente labrados que están y por sus figuras raras, atestiguan ser de origen muy remoto." Esta información coincide con los reportes arqueológicos de un siglo después incluidos en este libro, que adjudican a la hoy Selva Zoque un uso como espacio ritual, específicamente por la notoria presencia de cuevas con vestigios rituales

Las ruinas encontradas, dice Loya:

[...] revelan la existencia de un pequeño pueblo fundado después de la conquista, porque sus materiales de construcción (ladrillos, mezcla, tejas etcétera) indican ser de origen reciente, puesto que es bien sabido que los antiguos pobladores de
América nunca usaban para sus construcciones estos materiales...

El pueblo con el que se toparon los topógrafos en 1890 es el mismo pueblo colonial, Santa María Magdalena de la Pita, que es presentado en este libro por el investigador Víctor Esponda, quien visitó y documentó el sitio en los noventa y del cual su compañero Del Carpio sospecha que podría ser de origen oaxaqueño.

Ojo: la información presentada por Esponda y la presentada por Del Carpio no coinciden, pero mientras que éste sólo presenta una especulación, Esponda presenta documentos que comprueban la adscripción administrativa del pueblo a la antigua Provincia de las Chiapas como parte de la Audiencia de los Confines. Hubiera sido bueno intercambiar y actualizar sus textos.

Más o menos por el mismo tiempo en el que los deslindadores se adentraron en la Selva Zoque, otros intereses económicos se manifestaron en esta región. En primera línea las monterías, cuya permanencia en la región se remonta a la segunda mitad del siglo XIX, vivieron un auge. Pero también el interés en la producción de café, como demuestra Rocío Ortiz, fue causa y razón del avance de las fincas en esta región.

Aunque supuestamente despoblada la región, en 1890 los topógrafos detectaron ya 67 propiedades que corresponden a los cuatro municipios: Cintalapa, Jiquipilas, Ocozocoautla y Quechula. Como su tarea consistía en separar la superficie baldía de la superficie propiedad de particulares y pueblos, realizaron un registro minucioso de los dueños, propiedades, extensión y títulos. De este registro resultó, no sólo que había en el área deslindada una superficie de 144000 hectáreas en manos de particulares y pueblos, sino que, al igual que las principales propiedades, correspondían a un grupo de familias de comerciantes y políticos de Tuxtla: los Farrera, los del Pino, los Cal y Mayor, los Moguel, los del Cueto y los Maldonado, cuyas propiedades rebasaban en cada caso las 10000 hectáreas, llegando, en el caso de la 
Montería La Venta de Maldonado, a una extensión de 17000 hectáreas. Con razón los políticos de esos años, pertenecientes a las mismas familias, le dieron a la región el nombre de Departamento El Progreso.

Otros inversionistas, pensando en grande, buscaron por estas tierras una comunicación interoceánica, sea utilizando los ríos o proyectando canales y ferrocarriles que iban a pasar por el Desierto (Selva Zoque) comunicando la costa atlántica tabasqueña con los esteros del Pacífico. No eran ideas del todo descabelladas: Quechula tenía ya cierta fama como puerto de río, donde salían y llegaban en lanchas las mercancías intercambiadas entre el centro del estado de Chiapas y Tabasco.

La historia de esta región resulta rica y variada. Para los interesados en esta zona, el libro ofrece referencias que comprueban una producción académica de por lo menos 60 años. Es en realidad sorprendente la cantidad y calidad de los estudios realizados en y sobre la zona zoque en el estado y en el área colindante de Oaxaca, aunque se han difundido poco frente a publicaciones que se refieren a otras zonas del estado. Espero que los esfuerzos multidisciplinarios para recuperar integralmente la historia económica, política, social y cultural de una región como la Selva Zoque, encuentren seguidores y continuidad porque, aun con la publicación de varios libros en años recientes, quedan muchas preguntas por contestar. Si me permiten, quisiera hacer algunas sugerencias para futuras actividades.

Por ejemplo, profundizar en las causas por las que la región fue, como dicen los arqueólogos, de colonización y refugio. Aunque bastante convincentes las dos explicaciones, siguen siendo deducciones especulativas. Cuando leí el título del libro que inicia con "Medio ambiente", yo me imaginaba una perspectiva que finalmente el documento no llega a satisfacer. Más allá del registro de la fauna y la flora, y de ofrecer un llamado a su conservación, pensaba yo en otros factores que deben haber influido no sólo en la flora, la fauna y la conformación geotectónica, sino en los acontecimientos sociales que suponen los arqueólogos: pienso en el clima, en un estudio cronológico del clima para ser preciso. Formas de asentamiento, formas de aprovechamiento de la tierra, tienen una íntima relación con el factor clima, y el análisis de los cambios climáticos puede explicar muchos fenómenos aparentemente inexplicables. Sería conveniente la creación de una cadena de pruebas dendrocronológicas, es decir, de muestras de maderas, que permiten leer el clima durante los años de su crecimiento. Esta técnica permite regresar, en el mejor de los casos, miles de años y reconstruir los impactos del clima sobre la naturaleza y el hombre. En nuestro caso, sus resultados seguramente enriquecerían la discusión sobre los movimientos demográficos precoloniales.

Pero también quisiera sugerir otros temas que reclaman estudios multidisciplinarios: la creación y el impacto social y ambiental de la importante presa Malpaso; o los antecedentes y sucesos en la trágica desaparición de Juan del Grijalva y su reaparición como Nuevo Juan de Grijalva en forma de una de las 11 ciudades rurales proyectadas por el gobierno del estado en coordinación con la ONU, un experimento que parece revivir viejas prácticas coloniales de control sobre la población rural.

Como recomendación: intensificar la discusión interdisciplinar. Se nota que este libro, con el loable esfuerzo de juntar y presentar los resultados de especialistas de diferentes disciplinas, aún no ha llegado a un punto de pospresentación de sus textos donde se eviten contradicciones obvias. En especial estoy pensando en los artículos que especulan sobre la cuestión de límites entre Chiapas y Oaxaca, que no en todo momento cumplen con el rigor científico y que no aprovecharon información presentada por otros coautores. Creo que hubiera sido aún más fructífero retrabajar las ponencias originales entre todas y todos los autores, integrando sus resultados antes de publicarlos. 